\title{
A Case of Eccrine Nevus
}

\author{
Min Ju Kang, M.D., Dong Soo Yu, M.D., Jin Wou Kim, M.D. \\ Department of Dermatology, College of Medicine, The Catholic University of Korea, Seoul, Korea
}

Eccrine nevi are very rare cutaneous lesions which may or may not be accompanied by localized hyperhidrosis. Histological findings usually reveal a slightly increased number of eccrine glands without any other abnormalities. Herein we present a case of eccrine nevus not associated with localized hyperhidrosis on the left wrist of a 6-year-old girl. The lesion was a brownish, ovoid plaque approximately $1.0 \times 1.5 \mathrm{~cm}$ in size, with a hyperkeratotic, slightly scaly papule in the center. It was treated by surgical excision.

(Ann Dermatol (Seoul) 20(1) 29 31, 2008)

Key Word: Eccrine nevus

\section{INTRODUCTION}

Eccrine nevus is a rare disease, which may be present at birth or at an early age. It is more often associated with localized hyperhidrosis, while cases not associated have also been reported. It is usually characterized histologically by the increase in number or size of structurally normal eccrine glands. We report a case of a 6-year-old girl who had a solitary lesion on the left wrist that was not accompanied by other symptoms.

\section{CASE REPORT}

A 6-year-old girl with no significant past medical history presented with an asymptomatic, solitary lesion on her left wrist. On examination, there was an approximately $1.0 \times 1.5 \mathrm{~cm}$-sized, well-circumscribed, ovoid, brownish plaque, with a centrally located hyperkeratotic and slightly scaly papule (Fig. 1). Biopsy findings revealed slightly increased numbers of eccrine glands without any other abnormalities, consistent with an eccrine nevus (Fig. 2).

Received November 3, 2006

Accepted for publication January 12, 2008

Reprint request to: Dong Soo Yu, M.D., Department of Dermatology, Uijeongbu St. Mary's Hospital, 65-1, Geumodong, Uijeongbu 480-130, Korea. Tel: 82-31-820-3123, Fax:82-31-846-4799, E-mail: frank@medimail.co.kr
Although there were no symptoms, the lesion was removed by surgical excision, and there has been no recurrence in the year after treatment.

\section{DISCUSSION}

Eccrine nevi present as various clinical forms, some with a linear or zosteriform arrangement of papules, others without any overlying skin abnormalities ${ }^{1}$. Localized hyperhidrosis may be present, in which case, skin changes are not usually found. Patients most often present in childhood and may have congenital lesions; however, cases presenting at advanced ages have been reported. These lesions are found equally in men and women, and the most common location is the forearm ${ }^{2}$. In our patient, there was a solitary lesion on the left wrist, in the form of a brownish plaque with a centrally located hyperkeratotic papule and no associated hyperhidrosis.

Eccrine nevi are diagnosed histologically, with findings showing solely an increase in size and/or number of structurally normal eccrine glands. There have been reports however, of cases with structural malformations, such as contorted ducts, pseudobasaloid cell nests, or adenomatous changes ${ }^{3}$. Although hyperhidrosis was not present in our patient, many cases are associated with increased sweating. The differential diagnoses of such cases include eccrine angiomatous hamartomas, sudoriparous angiomas, 

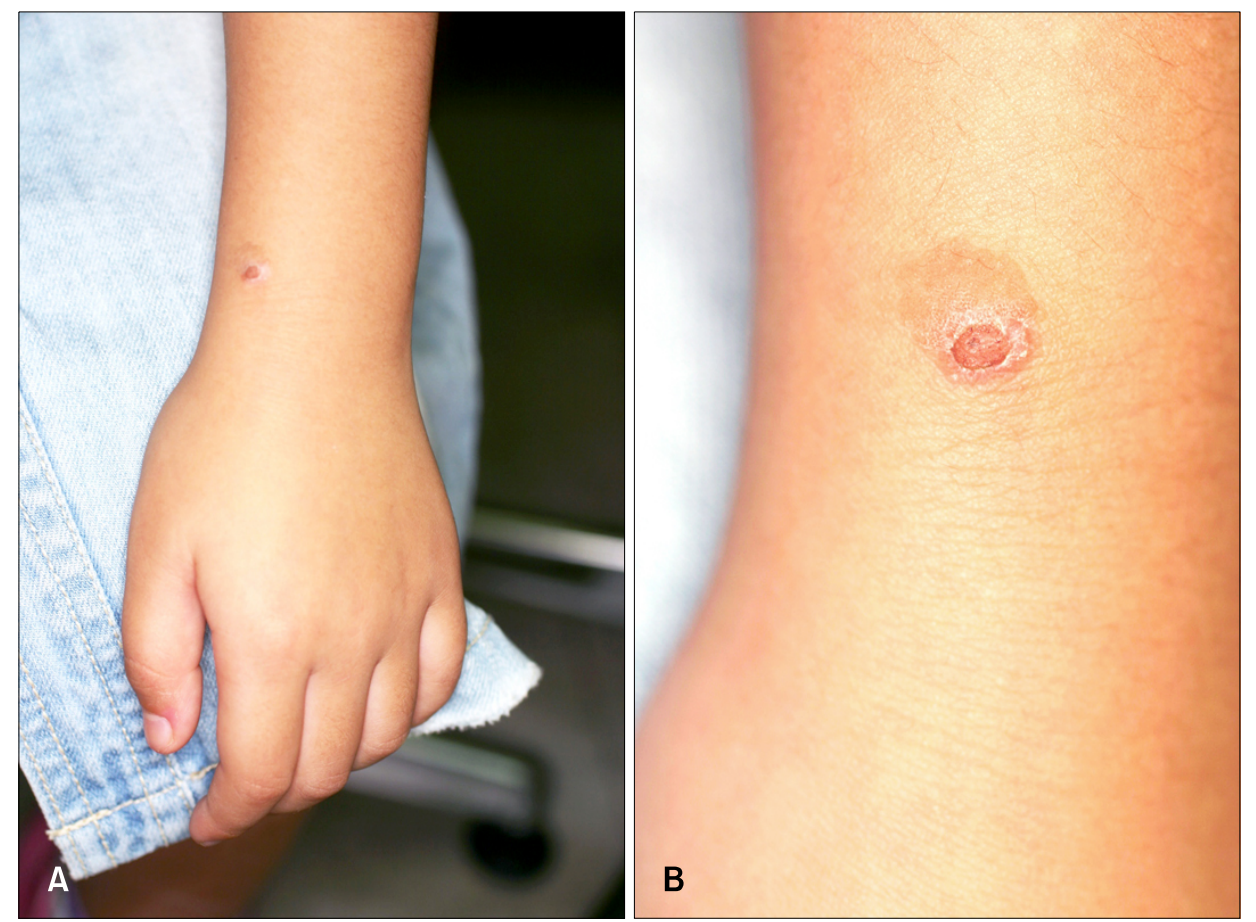

Fig. 1. (A) Brownish plaque approximately $1.0 \times 1.5 \mathrm{~cm}$ in size, ovoid shaped, with a hyperkeratotic, slightly scaly papule in the center, located on the left wrist. (B) Close-up view.
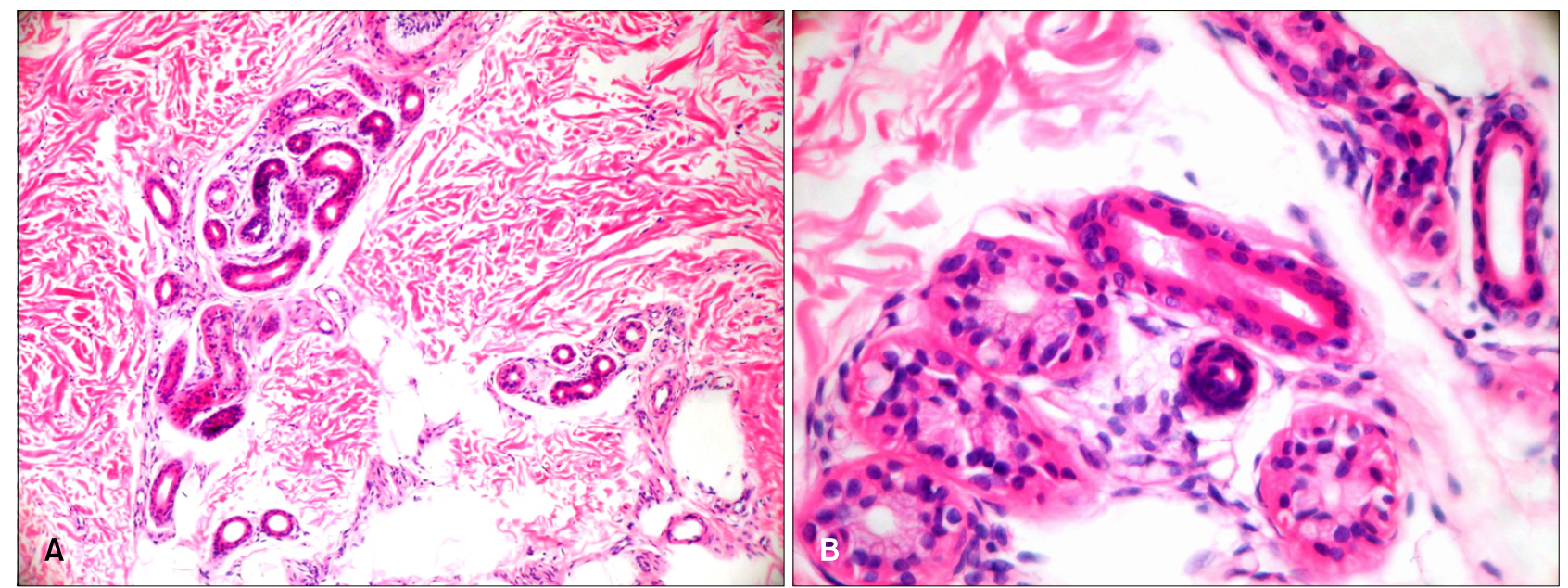

Fig. 2. (A) Slight increase in number of eccrine glands without any other abnormalities (Hematoxylin-eosin, $\times 100$ ). (B) Magnified view shows proliferation of eccrine glands (Hematoxylin-eosin, $\times 400$ ).

and eccrine nevi ${ }^{2}$. Eccrine angiomatous hamartoma $(\mathrm{EAH})$ is a benign disease characterized by increased numbers of eccrine glands and numerous papillary channels ${ }^{4}$. It most often presents on the extremities as a painful, solitary, flesh-colored, bluebrown, or reddish nodule or plaque. Hyperhidrosis occurs in approximately one out of every three patients, and hypertrichosis may also be associated. In cases of sudoriparous angioma, the angiomatous component is predominant, with associated eccrine dilatation ${ }^{2}$. Lesions are usually found on the lower extremities, and are also associated with pain, hyperhidrosis, hyperpigmentation, and compressibility. The compressible nature of these lesions may cause 
confusion with the blue rubber bleb nevus syndrome; however, unlike sudoriparous angiomas, this syndrome is associated with gastrointestinal venous malformations. Idiopathic unilateral hyperhidrosis must also be differentiated from eccrine nevus. Clinically, it presents as a well-demarcated area of hyperhidrosis without any associated cutaneous abnormality ${ }^{5}$. It is usually less than $10 \times 10 \mathrm{~cm}$ in size, and occurs mainly on the face or arms of healthy individuals of all age groups, with short episodes of hyperhidrosis. These episodes are sometimes precipitated by heat, stress, or food intake. The only abnormality found on biopsy of our case was hypertrophy of the eccrine glands, and while the presence of hypertrophy or hyperplasia of eccrine glands is considered to be integral to the diagnosis of eccrine nevi, cases of hyperhidrosis with hypertrophic glands have been included in reports of idiopathic lesions ${ }^{5}$. Therefore, idiopathic cases of hyperhidrosis with eccrine gland hypertrophy should be designated as cases of eccrine nevi, reserving the former term for lesions where no histologic abnormality is identified. As knowledge of sweat gland pathophysiology is advanced, improved categorization of these lesions may be possible.

The usual treatment of eccrine nevi is surgical excision $^{3}$. If localized hyperhidrosis is present, it may be treated with topical aluminum chloride, or systemic agents with anticholinergic properties ${ }^{2,6}$. Iontophoresis is another option, but is usually reserved for palmar/plantar hyperhidrosis, and successful treatment with botulinum toxin has been reported $^{2,7}$. As with any other treatment, potential benefit should be weighed against possible side effects. Although there were no symptoms in our patient, due to cosmetic reasons, surgical excision was performed. The lesion was effectively removed, and no recurrence has been noted within one year of treatment.

\section{REFERENCES}

1. Takahashi S, Sato T. The first case of eccrine nevus in Japan, and with reference two review of the original literatures on this nevus and the nosologic study. Jap J Derm 1978;88:715-719.

2. Kawaoka JC, Gray J, Schappell D, Robinson-Bostom L. Eccrine nevus. J Am Acad Dermatol 2004;51: 301-304.

3. Jung WK, Lee JS, Jung MJ, Whang KW, Kim YK. A case of eccrine nevus. Ann Dermatol 1995; 7:270-272.

4. Elder DE, Elenirsas R, Johnson BL, Murphy GF. Histopathology of the skin. 9th ed. Philadelphia: JB Lippincott, 1990:609.

5. Ghali FE, Fine JD. Idiopathic localized unilateral hyperhidrosis in a child. Pediatr Dermatol 2000; 17:25-28.

6. Silver SG, Ho VCY. Benign epithelial tumors. In: Freedberg IM, Eisen AZ, Wolff K, Austen KF, Goldsmith LA, Katz SI, editors. Fitzpatrick's dermatology in general medicine. 6th ed. New York: McGraw-Hill, 2003:774-775.

7. Vazquez MR, Gomez de la Fuente E, Fernandez JG, Martin FJ, Estebaranz JL, Moraleda FP. Eccrine naevus: case report and literature review. Acta Derm Venereol 2002;82:154-156. 